\title{
Effect of stress relaxation in two different preactivation methods of beta-titanium T-loops: bends vs. continuous curvature
}

\author{
Sergei Godeiro Fernandes Rabelo Caldas ${ }^{\mathrm{a}, *}$, Renato Parsekian Martins ${ }^{\mathrm{b}}$, \\ Marcela Emílio de Araújo ${ }^{c}$, Marília Regalado Galvão ${ }^{\mathrm{d}}$, \\ José Maurício dos Santos Nunes Reis ${ }^{\mathrm{e}}$, Lídia Parsekian Martins ${ }^{\mathrm{f}}$ \\ ${ }^{a}$ Adjunct Professor, Department of Dentistry, UFRN-Federal University of Rio Grande do Norte, Natal, Rio Grande do Norte, Brazil \\ ${ }^{\mathrm{b}}$ Private practice and part-time adjunct faculty of the Orthodontics Graduate Program, UNESP-Univ Estadual Paulista, Araraquara School of Dentistry, \\ Araraquara, São Paulo, Brazil \\ ${ }^{\mathrm{c}}$ MSc Student, Department of Dentistry, UFRN-Federal University of Rio Grande do Norte, Natal, Rio Grande do Norte, Brazil \\ ${ }^{\mathrm{d}}$ Adjunct Professor, Department of Dentistry, UFRN-Federal University of Rio Grande do Norte, Natal, Rio Grande do Norte, Brazil \\ e Professor, Department of Dental Materials and Prosthesis, UNESP-Univ Estadual Paulista, Araraquara School of Dentistry, Araraquara, São Paulo, Brazil \\ ${ }^{\mathrm{f}}$ Professor, Department of Pediatric Dentistry, UNESP-Univ Estadual Paulista, Araraquara School of Dentistry, Araraquara, São Paulo, Brazil
}

\section{A R T I C L E I N F O}

\section{Article history:}

Received 15 June 2017

Received in revised form

4 August 2017

Accepted 6 August 2017

\section{Keywords:}

Beta-titanium

Preactivation

Stress relaxation

T-loop

\begin{abstract}
A B S T R A C T
Objective: Assess the changes in the force system of T-loop springs (TLSs) preactivated by bends and curvature, when secured in place with a constant strain over time.

Materials and Methods: A total of 120 TLSs with dimensions 6 × $10 \mathrm{~mm}$, produced out of $0.017 \times 0.025$-inch TMA, were randomly divided into two groups of 60 TLSs, each according to what preactivation was going to be used, concentrated bends or gradual curvature. Subgroup 1 was tested immediately and the remaining subgroups were tested after they were secured at 5 -mm activation for different periods of time in an interbracket distance of $23 \mathrm{~mm}$. Subgroups 2, 3, 4, 5, and 6 were kept activated for 24, 48, and 72 hours, 1 and 2 weeks, respectively. Using a moment transducer coupled to a digital extensometer indicator adapted to a universal testing machine, the amount of horizontal force, moment, and moment-to-force (MF) ratios were recorded.

Results: Both groups showed a decrease in force levels over time $(P<0.001$ and 0.005 for bend and curvature preactivation, respectively), but with different behaviors. The group preactivated by bends showed a reduction in moments over time $(P<0.001)$, whereas the group preactivated by curvature did not $(P=0.410)$. The MF ratio has not changed over time in either group.

Conclusions: The stress-relaxation effect is more evident on group preactivated by bends.
\end{abstract}

(c) 2017 World Federation of Orthodontists.

\section{Introduction}

Orthodontists often use sliding or loop mechanics for space closure resulting from the extraction sites. Among the loops normally used, some may be simple, such as the vertical loop [1,2], or more elaborate, such as the T-loop spring (TLS) [3]. Nowadays, the TLSs are preferred to be produced from $\beta$-Ti wires, which greatly improves the physical properties of these springs [4,5].

A TLS with normally used sizes $(6-7 \times 10 \mathrm{~mm})$ cannot produce moment-to-force (MF) ratios that are high enough to produce

\footnotetext{
* Corresponding author: UFRN-Federal University of Rio Grande do Norte, Health Science Center, Department of Dentistry, Avenida Senador Salgado Filho, $\mathrm{n}^{\mathrm{o}} 1787$, 59056-000, Natal/RN - Brazil.

E-mail address: sergeirabelo@icloud.com (S.G.F.R. Caldas).
}

translation out of their activation moment [1,3]; thus, more moment is required, which could be produced by gable bends [6-14] or curvature (residual moment) [6,9,14-18]. These adjustments made before engaging the TLS to the brackets to increase the MF ratio are called preactivation. Both preactivations, by bends or by curvature, have specific techniques for standardization, allowing them to replicate the system of forces desired that were previously measured $[10,18]$.

Regardless of which preactivation is used, these springs are attached to the brackets in the patients mouth over a long period and are subjected to a constant strain. This strain could cause a permanent deformation (Fig. 1), which has been named stress relaxation [19-21]. This phenomenon can cause changes in the original shape of the spring, changing the original preactivation, thus changing the system of forces planned for tooth movement. 


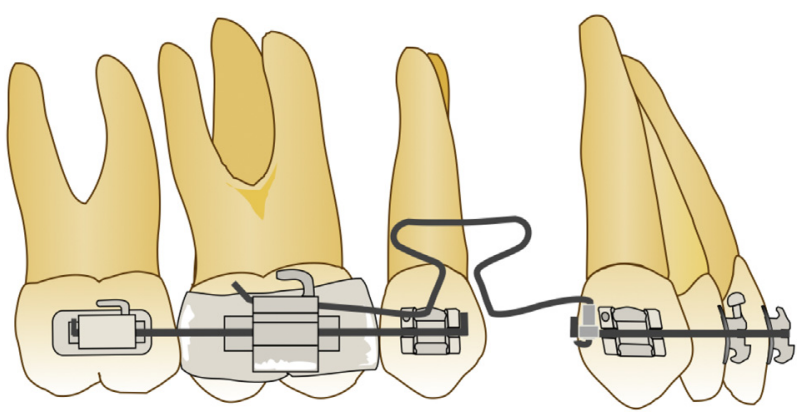

Fig. 1. TLS engaged to brackets (loaded in an opposite direction to its preactivation).

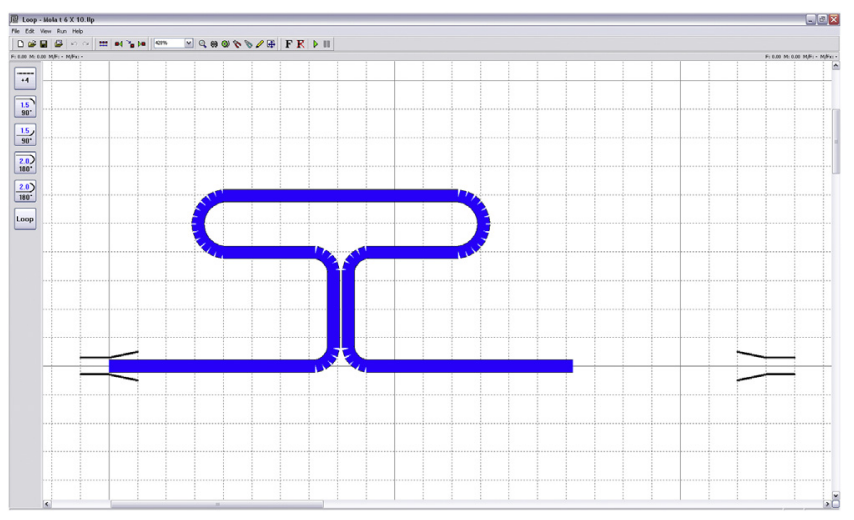

Fig. 2. Template developed in the Loop software (dHAL Orthodontic Software, Athens, Greece) used for the design of the TLS. The software allows the template to be printed in a $1: 1$ ratio. Each square measures $1 \mathrm{~mm}^{2}$.

This effect has already been reported in TLSs preactivated by concentrated bend [7], but there is no evidence that both preactivations (bends and curvature) respond the same way to stress relaxation. Although bends tend to concentrate stress on specific areas of the wire, causing spacing and unstable displacement of the crystal structure to be dissipated over time $[7,19,21]$, a gradual curvature could distribute these stresses throughout the entire wire, which could reduce the effect of stress relaxation.
Thus, the aim of this article was to assess the changes in the force system of TLSs preactivated by concentrated bends and curvature, when secured in place with a constant strain over time.

\section{Materials and methods}

A total of 120 TLSs were bent by one of the authors (SGFRC) using a "Marcotte" plier (Hu-Friedy dental instruments, Chicago, IL) out of straight pieces of $0.017 \times 0.025$-inch $\beta$-Ti (TMA; Ormco Corporation, Glendora, CA) wires, following a custom template (Fig. 2). The TLSs had dimensions of $6 \mathrm{~mm}$ in height and $10 \mathrm{~mm}$ of length and were randomly divided into two groups of 60 TLSs each according to what preactivation was going to be used, concentrated bends or gradual curvature (Fig. 3).

To perform the preactivations, the TLSs of the group preactivated by concentrated bends were didactically marked in six points, whereas in the TLSs of the group preactivated by gradual curvature only four points were used (Fig. 4). In both groups, using a Marcotte plier, the points 1 and 2 were compressed until the horizontal extension of the TLS showed $90^{\circ}$ of angulation between them. At points 3 and 4 , a bend was made until the extremity of the horizontal extensions could touch slightly the vertical extremities of the TLS. In the bends preactivation group, at points 5 and 6 ( $3 \mathrm{~mm}$ of the central vertical extensions of the TLS), a bend was made until the horizontal extensions were permanently deformed and touching the vertical extremities of the TLS. Already, for the group preactivated by curvature, the horizontal extensions continuous to positions 3 and 4 were gradually curved until the vertical extremities of the TLS remained touching. In both groups, stresses incorporated by the preactivation were relieved and the TLSs were placed in a neutral position and an active simulation performed. After this, the TLSs should be exactly on the template (Fig. 3). If they are not, they should be readjusted until they fit.

Each group was subdivided into six subgroups according to the time of evaluation. Subgroup 1 was tested immediately and the remaining subgroups were tested after they were secured at 5-mm activation for different periods of time in an interbracket distance (IBD) of $23 \mathrm{~mm}$, mimicking a clinical situation, on a custom-made device specifically made for this purpose (Fig. 5). Subgroups 2, 3, 4,5 , and 6 were kept activated for 24, 48, and 72 hours, 1 and 2 weeks, respectively.

A universal testing machine (EMIC, São José dos Pinhais, Brazil), equipped with a load cell of $0.1 \mathrm{kN}$, was coupled to a
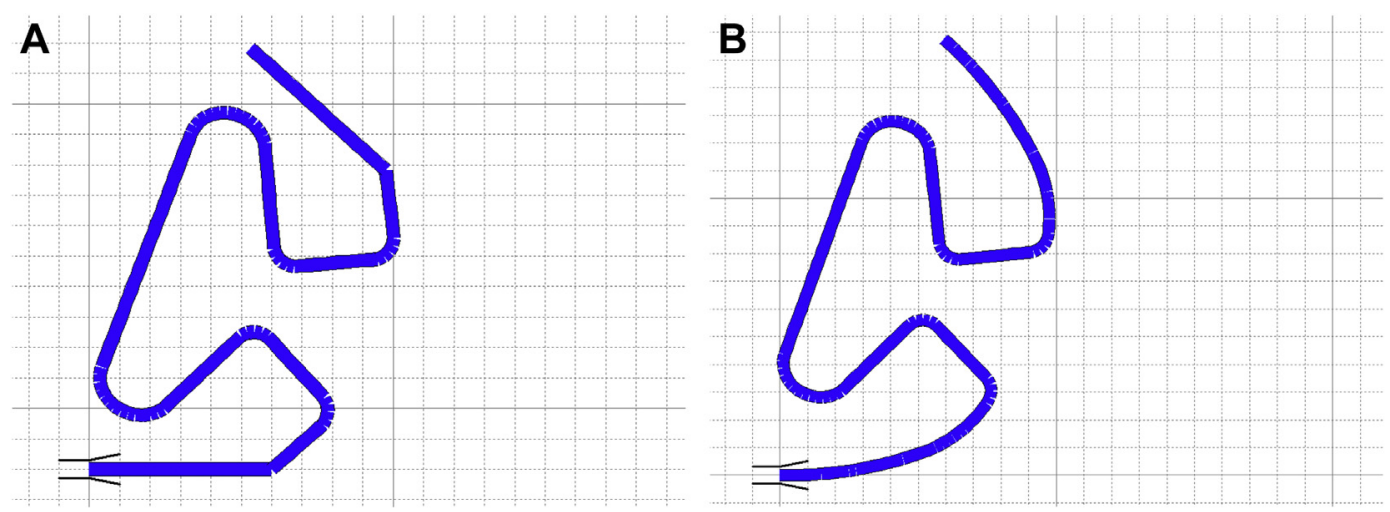

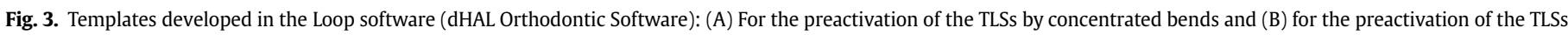
by gradual curvature. 


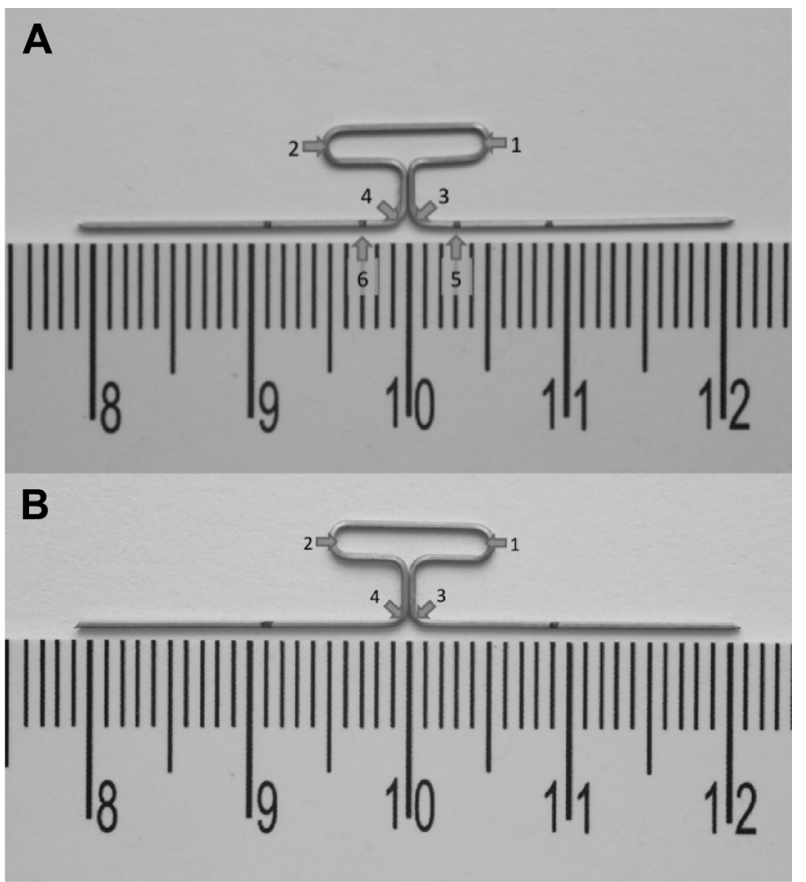

Fig. 4. Preactivation points of the TLSs: (A) For concentrated bend preactivation and (B) for gradual curvature preactivation.

moment transducer and a digital extensometer indicator (Transdutec, São Paulo, Brazil) for the tests. The speed used for the test was $5 \mathrm{~mm} / \mathrm{min}$ and the digital extensometer's excitation and sensitivity was set to $5 \mathrm{~V}$ and $0.5 \mathrm{mV} / \mathrm{V}$, respectively. This same setup has been used previously in recent publications $[6,7,22]$.

For the test, the TLSs were positioned symmetrically in an IBD of $23 \mathrm{~mm}$, and at this distance (confirmed with a digital caliper) the device was zeroed. To ensure correct horizontal activation and centralization of the TLSs, $9 \mathrm{~mm}$ were measured from the center of the loop toward each extremity of the horizontal extensions, and were marked with a permanent marker (Fig. 6). Those markings would allow the TLSs to be correctly positioned.

After a horizontal activation of $5 \mathrm{~mm}$, the horizontal force and moment developed were recorded for every $0.5 \mathrm{~mm}$ of deactivation; at one extremity of the TLSs, and the MF ratios were calculated.

\subsection{Statistical analysis}

SPSS version 16.0 (SPSS Inc., Chicago, IL) statistical analysis software was used in this study. The Kolmogorov-Smirnov

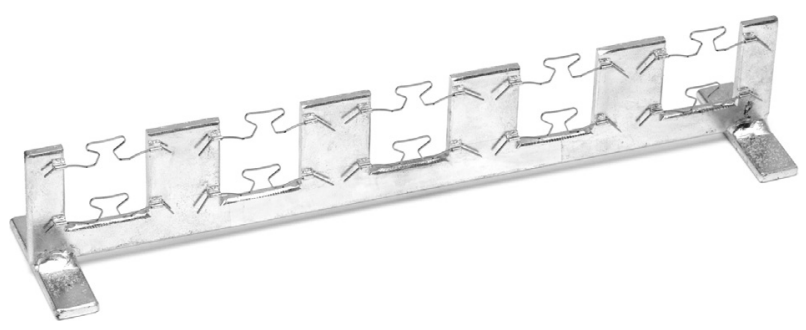

Fig. 5. Custom-made device to keep the TLSs activated $5 \mathrm{~mm}$.

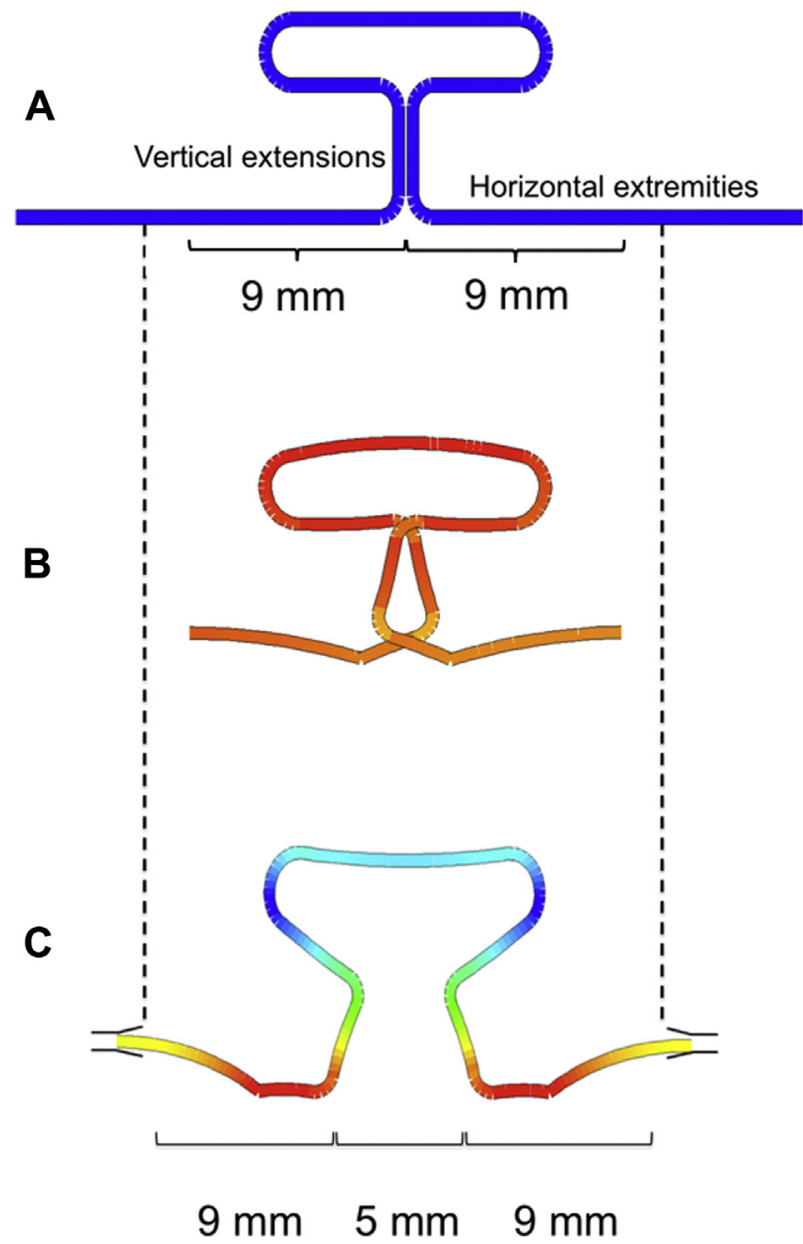

Fig. 6. (A) Loop horizontal dimension stops were marked to ensure the correct activation and TLS centralization. (B) Neutral position of the TLS simulated by the Loop software. (C) TLS shape simulated by the Loop software when positioned symmetrically in an IBD of $23 \mathrm{~mm}$ and activated $5 \mathrm{~mm}$. Colored areas reflect stress distribution over the wire, going from red, which are high stress areas, to dark blue, which are low stress areas.

test indicated normal distributions and the Levene test showed that all variables had similar variances, except the MF ratios.

The multivariate profile analysis using the procedure for analysis of repeated measures was used to detect differences of forces, moments, and MF ratios among the subgroups (G1 to G6) within each group (concentrated bend and curvature). This analysis compares the total profile, or deactivation pattern, of a whole group in relation to time and deactivation, and should not be mistaken by a comparison of the springs' behavior in a specific activation. If a difference was found, Tukey post hoc test was used to identify them among the subgroups.

Independent t-test was used to identify differences between the two groups in changes of force, moments, and MF ratios with time.

\section{Results}

Both groups showed a decrease in force levels over time. In the bends preactivation group, subgroup 1 had an overall force intensity greater than the other five subgroups $(P<0.001)$, which did 
Table 1

General profiles and subgroup differences means for force developed by both groups and subgroups

\begin{tabular}{|c|c|c|c|c|c|c|c|c|c|c|c|c|}
\hline \multirow{3}{*}{$\begin{array}{l}\text { Group } \\
\text { Subgroup }\end{array}$} & \multicolumn{12}{|c|}{ Force } \\
\hline & \multicolumn{3}{|c|}{ Concentrated bend } & \multicolumn{3}{|c|}{ Curvature } & \multirow[t]{2}{*}{ Subgroup difference } & \multicolumn{2}{|c|}{ Concentrated bend } & \multicolumn{2}{|c|}{ Curvature } & \multirow[t]{2}{*}{$P^{*}$} \\
\hline & Mean & & SD & Mean & & SD & & Mean & SD & Mean & SD & \\
\hline 1 & 267.6 & A & 105.2 & 228.4 & A & 115.1 & & & & & & \\
\hline 2 & 200.7 & $\mathrm{~B}$ & 111.5 & 197.3 & A B & 112.8 & $1-2$ & 66.9 & 42.0 & 31.1 & 32.2 & 0.047 \\
\hline 3 & 197.8 & $\mathrm{~B}$ & 107.8 & 191.4 & $\mathrm{~B}$ & 110.3 & $2-3$ & 2.9 & 49.2 & 5.9 & 45.6 & 0.89 \\
\hline 4 & 200.5 & $\mathrm{~B}$ & 111.1 & 184.5 & $\mathrm{~B}$ & 107.4 & $3-4$ & -2.7 & 38.0 & 6.9 & 37.6 & 0.578 \\
\hline 5 & 186.1 & B & 104.8 & 185.9 & B & 109.7 & $4-5$ & 14.4 & 41.1 & -1.4 & 45.2 & 0.425 \\
\hline 6 & 186.2 & B & 110.4 & 189.9 & B & 110.9 & $5-6$ & -0.1 & 31.1 & -4.0 & 38.6 & 0.808 \\
\hline$P^{\dagger}$ & $<0.001$ & & & 0.005 & & & & & & & & \\
\hline
\end{tabular}

$\mathrm{SD}$, standard deviation.

* Independent t-test (line intergroup).

$\dagger$ Multivariate profile analysis (column intragroup).

not show differences among them. For the group preactivated by curvature, the force decreased and was significantly changed only from the third subgroup on $(P=0.005)$. Regarding the amount of horizontal force lost over time, the difference between the preactivations was significant $(P<0.047)$ only between times 1 and 2 . With that exception, both groups showed similar behavior over time (Table 1 and Fig. 7).

The group preactivated by bends showed a reduction in moments over time $(P<0.001)$, whereas the group preactivated by curvature did not $(P=0.410)$. In the group preactivated by bends, the moments produced in subgroup 1 were higher than the other five subgroups, which were not different among them. Similar to what happened with the force levels, the amount of moment loss over time was significant $(P<0.002)$ only between the first and second time periods. From that point on, both groups showed similar behavior over time (Table 2 and Fig. 8).

The MF ratio has not changed over time in either group, and no differences were found between the two groups (Table 3 and Fig. 9).

\section{Discussion}

Horizontal force decreased in both groups but with different behaviors. The group preactivated by concentrated bends showed a decrease in the level of the horizontal force within the first 24 hours, whereas in the group preactivated by curvature, the reduction was more gradual, being significant only after 48 hours. This difference can be explained by the preactivation's behavior in relation to stress relaxation over time. When concentrated bends are subjected to a constant strain, they will converge stress to specific places in the wire, causing dislocations and unstable displacements in the crystalline structure of the alloy, all of which tend to rearrange themselves over time due to stress relaxation [7,19-21]. On the other hand, when a gradual curvature is used, stress is distributed over the entire extent of curvature, diminishing the effect of stress relaxation. Previous reports have shown that when the preactivation intensity is increased (without proper adjustments to the TLS), a greater amount of overlap of the vertical extensions of the TLS in neutral position can happen, producing a greater activation and higher horizontal force [1]. Thus, the faster

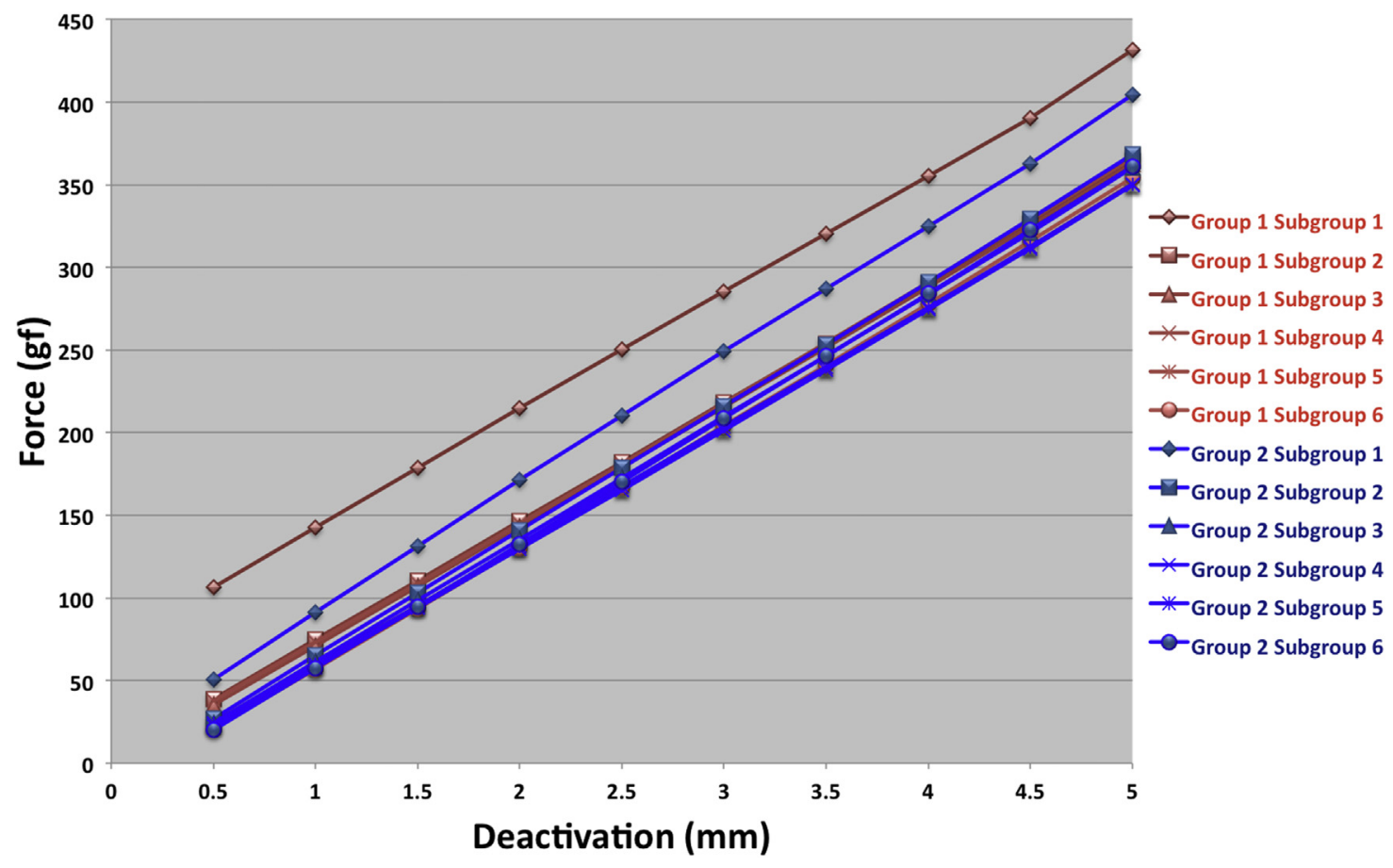

Fig. 7. Chart depicting the average forces produced, during deactivation from 5 to $0.5 \mathrm{~mm}$, for the groups and subgroups tested. 
Table 2

General profiles and subgroup differences means for moment developed by both groups and subgroups

\begin{tabular}{|c|c|c|c|c|c|c|c|c|c|c|c|}
\hline \multirow{3}{*}{$\begin{array}{l}\text { Group } \\
\text { Subgroup }\end{array}$} & \multicolumn{11}{|c|}{ Moment } \\
\hline & \multicolumn{3}{|c|}{ Concentrated bend } & \multicolumn{2}{|c|}{ Curvature } & \multirow{2}{*}{$\begin{array}{l}\text { Subgroup } \\
\text { difference }\end{array}$} & \multicolumn{2}{|c|}{ Concentrated bend } & \multicolumn{2}{|c|}{ Curvature } & \multirow[t]{2}{*}{$P^{*}$} \\
\hline & Mean & & SD & Mean & SD & & Mean & SD & Mean & SD & \\
\hline 1 & 1932.6 & A & 259.2 & 1941.0 & 272.9 & & & & & & \\
\hline 2 & 1537.9 & $\mathrm{~B}$ & 249.9 & 1919.9 & 336.8 & $1-2$ & 394.7 & 208.4 & 21.2 & 251.5 & 0.002 \\
\hline 3 & 1471.3 & B & 239.3 & 1922.0 & 301.9 & $2-3$ & 66.6 & 278.7 & -2.1 & 270.2 & 0.583 \\
\hline 4 & 1616.5 & $\mathrm{~B}$ & 250.0 & 1912.9 & 317.5 & $3-4$ & -145.2 & 294.5 & 9.1 & 278.4 & 0.244 \\
\hline 5 & 1563.1 & $\mathrm{~B}$ & 206.7 & 1840.7 & 286.0 & $4-5$ & 52.8 & 150.8 & 72.2 & 312.7 & 0.861 \\
\hline 6 & 1636.4 & $\mathrm{~B}$ & 236.3 & 1775.4 & 288.9 & $5-6$ & -72.7 & 171.2 & 65.2 & 164.7 & 0.083 \\
\hline$P^{\dagger}$ & $<0.001$ & & & 0.410 & & & & & & & \\
\hline
\end{tabular}

SD, standard deviation.

* Independent t-test (line intergroup).

${ }^{\dagger}$ Multivariate profile analysis (column intragroup).

and larger relaxation of the preactivation by bends causes a faster and larger decrease in force (Table 1). A clinically relevant aspect of these findings is that the curvature preactivation allows a smaller decrease (38.5 gf) in the total force produced by the TLS (by subtracting force values from subgroup 1 from 6 ) caused by the stress relaxation when compared with the bend preactivation group (81.4 gf), producing a more constant force. These force differences, however, were significant only in the first 24 hours, becoming similar after that period.

There was a reduction in intensity of the moments produced over time in the group preactivated by concentrated bends, whereas the moments in the group preactivated by curvature remained stable. Stress relaxation also can explain this behavior, because the lower moments are produced by decreasing the angulation of the TLS's horizontal extremities (and vice-versa) $[1,8,23-25]$. The differences between groups were quite similar to the horizontal force, because the relaxation was different in the first 24 hours and then became negligible.

The MF ratio was stable in both groups and insensitive over time. There could be differences among the subgroups; however, the power of our analysis was too low ( 0.29 and 0.47 for concentrated bends and curvature groups, respectively) to detect any differences.
Clinically, it is suggested that the force system is more stable in the absence of concentrated bends, which is more susceptible to relaxation over time. So, recommending that orthodontists activate these devices by gradual curvatures because it could produce a more controlled movement than when preactivation by concentrated bends is used [6].

\section{Conclusions}

With regard to the period of observation of this research:

1. Both preactivations tested suffer stress relaxation over time, modifying the horizontal force. The preactivation by concentrated bends showed an abrupt load decrease during the first 24 hours, whereas the preactivation by curvature shows a more gradual decrease.

2. The curvature preactivation was insensitive to changes in the moments produced, whereas in the bend preactivation, the decrease of the moments was abrupt in the first 24 hours.

3. The MF ratio was insensitive to the stress relaxation.

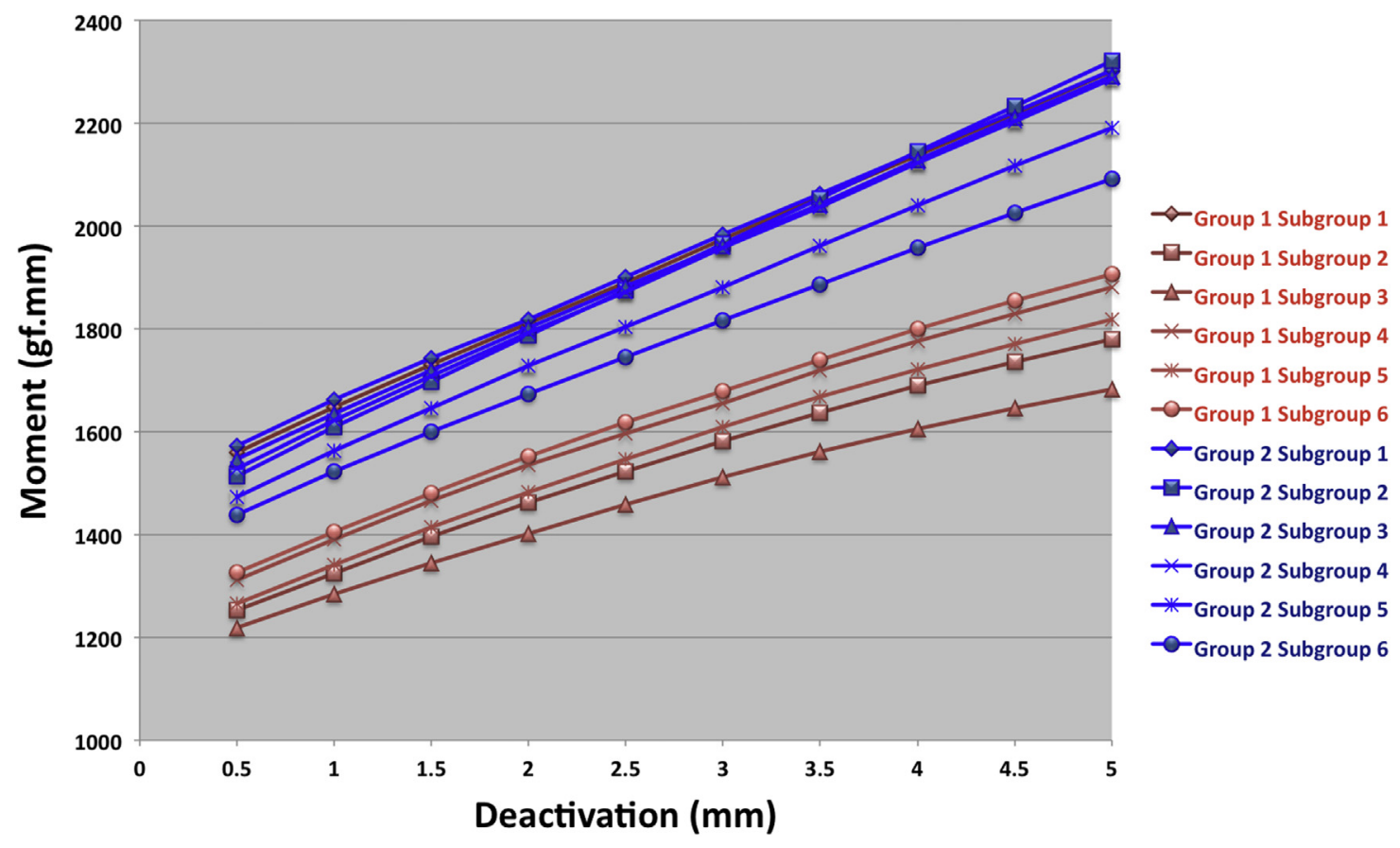

Fig. 8. Chart depicting the average moments produced, during deactivation from 5 to $0.5 \mathrm{~mm}$, for the groups and subgroups tested. 
Table 3

General profiles and subgroup differences means for MF ratio developed by both groups and subgroups

\begin{tabular}{|c|c|c|c|c|c|c|c|c|c|c|}
\hline \multirow{3}{*}{$\begin{array}{l}\text { Group } \\
\text { Subgroup }\end{array}$} & \multicolumn{10}{|c|}{ MF ratio } \\
\hline & \multicolumn{2}{|c|}{ Concentrated bend } & \multicolumn{2}{|c|}{ Curvature } & \multirow{2}{*}{$\begin{array}{l}\text { Subgroup } \\
\text { difference }\end{array}$} & \multicolumn{2}{|c|}{ Concentrated bend } & \multicolumn{2}{|c|}{ Curvature } & \multirow[t]{2}{*}{$P^{*}$} \\
\hline & Mean & SD & Mean & SD & & Mean & SD & Mean & SD & \\
\hline 1 & 8.3 & 3.2 & 12.7 & 13.3 & & & & & & \\
\hline 2 & 11.2 & 18.2 & -5.8 & 180.1 & $1-2$ & -2.9 & 3.5 & 18.6 & 57.6 & 0.271 \\
\hline 3 & 26.7 & 166.7 & 17.3 & 42.3 & $2-3$ & -15.5 & 53.1 & -23.1 & 58.4 & 0.765 \\
\hline 4 & 12.2 & 34.5 & 3.7 & 100.2 & $3-4$ & 14.5 & 55.3 & 13.6 & 31.5 & 0.966 \\
\hline 5 & 14.2 & 13.7 & 20.9 & 61.7 & $4-5$ & -1.9 & 11.4 & -17.2 & 37.4 & 0.243 \\
\hline 6 & 10.2 & 33.4 & 24.8 & 90.8 & $5-6$ & 4.2 & 9.4 & -4.0 & 37.2 & 0.512 \\
\hline$P^{\dagger}$ & 0.509 & & 0.220 & & & & & & & \\
\hline
\end{tabular}

$\mathrm{SD}$, standard deviation.

* Independent t-test (line intergroup).

$\dagger$ Multivariate profile analysis (column intragroup).

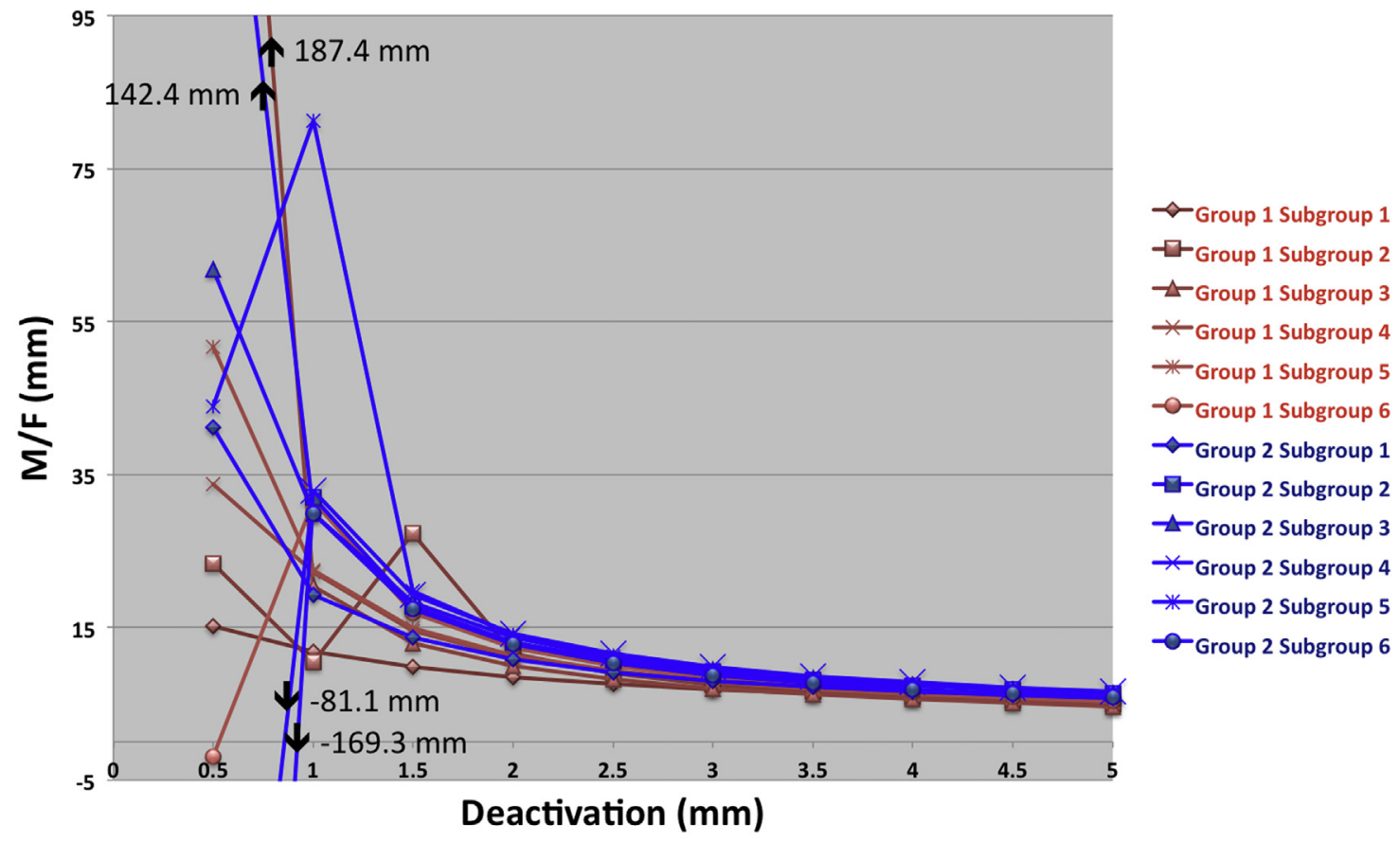

Fig. 9. Chart depicting the average MF ratios produced, during deactivation from 5 to $0.5 \mathrm{~mm}$, for the groups and subgroups tested.

\section{Acknowledgments}

Source of financial support: FAPESP (Process number 2008/ 07258-5, Fundação de Amparo à Pesquisa do Estado de São Paulo, SP, Brazil).

The authors deny any conflicts of interest.

\section{References}

[1] Burstone CJ, Koenig HA. Optimizing anterior and canine retraction. Am J Orthod 1976;70:1-19.

[2] Faulkner MG, Lipsett AW, el-Rayes K, Haberstock DL. On the use of vertical loops in retraction systems. Am J Orthod Dentofacial Orthop 1991;99:328-36.

[3] Burstone CJ. The segmented arch approach to space closure. Am J Orthod 1982;82:361-78.

[4] Burstone CJ, Goldberg AJ. Beta titanium: a new orthodontic alloy. Am J Orthod 1980;77:121-32.

[5] Burstone CJ. Variable-modulus orthodontics. Am J Orthod 1981;80:1-16.

[6] Caldas SGFR, Martins RP, Galvao MR, Vieira CIV, Martins LP. Force system evaluation of symmetrical beta-titanium T-loop springs preactivated by curvature and concentrated bends. Am J Orthod Dentofacial Orthop 2011;140:e53-8.
[7] Caldas SGFR, Martins RP, Viecilli RF, Galvao MR, Martins LP. Effects of stress relaxation in beta-titanium orthodontic loops. Am J Orthod Dentofacial Orthop 2011;140:e85-92.

[8] Faulkner MG, Fuchshuber P, Haberstock D, Mioduchowski A. A parametric study of the force/moment systems produced by T-loop retraction springs. J Biomech 1989;22:637-47.

[9] Manhartsberger C, Morton JY, Burstone CJ. Space closure in adult patients using the segmented arch technique. Angle Orthod 1989;59:205-10.

[10] Marcotte M. Biomechanics in orthodontics. Philadelphia, PA: BC Decker; 1990.

[11] Martins RP, Buschang PH, Gandini Jr LG. Group A T-loop for differential moment mechanics: an implant study. Am J Orthod Dentofacial Orthop 2009; 135:182-9.

[12] Martins RP, Buschang PH, Gandini Jr LG, Rossouw PE. Changes over time in canine retraction: an implant study. Am J Orthod Dentofacial Orthop 2009;136:87-93.

[13] Martins RP, Buschang PH, Martins LP, Gandini Jr LG. Optimizing the design of preactivated titanium T-loop springs with Loop software. Am J Orthod Dentofacial Orthop 2008;134:161-6.

[14] Martins RP, Buschang PH, Viecilli R, dos Santos-Pinto A. Curvature versus v-bends in a group B titanium T-loop spring. Angle Orthod 2008;78:517-23.

[15] Hoenigl KD, Freudenthaler J, Marcotte MR, Bantleon HP. The centered T-loop - a new way of preactivation. Am J Orthod Dentofacial Orthop 1995; 108:149-53.

[16] Kuhlberg AJ, Burstone CJ. T-loop position and anchorage control. Am J Orthod Dentofacial Orthop 1997;112:12-8.

[17] Viecilli RF. Self-corrective T-loop design for differential space closure. Am ] Orthod Dentofacial Orthop 2006;129:48-53. 
[18] Burstone CJ, van Steenbergen E, Hanley KJ. Modern edgewise mechanics \& the segmented arch technique. Glendora, CA: Ormco Co.; 1995.

[19] Anusavice KJ, Brantley WA. Physical properties of dental materials. In: Anusavice KJ, editor. Phillips science of dental materials. 11th ed. St. Louis, MO: WB Saunders; 2003. p. 25.

[20] Earthman JC. Creep and stress-relaxation testing. In: Wiley, editor. Mechanical testing and evaluation. New Jersey, Ohio: ASM Handbook; 2000. p. 359-424.

[21] William D, Callister J. Materials science and engineering: an introduction. Hoboken, NJ: Wiley; 2006.

[22] Martins RP, Caldas SG, Ribeiro AA, Vaz LG, Shimizu RH, Martins LP. Differences in the force system delivered by different beta-titanium wires in elaborate designs. Dental Press J Orthod 2015;20: 89-96.

[23] Chen J, Markham DL, Katona TR. Effects of T-loop geometry on its forces and moments. Angle Orthod 2000;70:48-51.

[24] Lim Y, Quick A, Swain M, Herbison P. Temperature effects on the forces, moments and moment to force ratio of nickel-titanium and TMA symmetrical T-loops. Angle Orthod 2008;78:1035-42.

[25] Rose D, Quick A, Swain M, Herbison P. Moment-to-force characteristics of preactivated nickel-titanium and titanium-molybdenum alloy symmetrical T-loops. Am J Orthod Dentofacial Orthop 2009;135: 757-63. 